\title{
Baseline, Cross-sectional Survey of Knowledge, Attitudes, and Practices Related to Efficient Use of Government Resources in the Health Sector in Malawi
}

\section{Aulive Msoma ${ }^{1}$, Rachel Lenzi ${ }^{2}$, Chrissy Godwin ${ }^{2}$, Harold Fote ${ }^{1}$, Benjamin Ndovi ${ }^{1}$, Heather Chotvacs $^{2}$, Gretchen Thompson ${ }^{2}$}

1. USAID/Health Communication for Life Project, implemented by FHI 360, Lilongwe, Malawi

2. FHI 360 Global Health, Population and Nutrition Group, Durham, North Carolina, USA

\begin{abstract}
\section{Background}

Misuse of government resources is a challenge within the health sector that can be addressed by increasing public demand for accountability, reporting suspected misuse of resources, and other client-driven changes. This study was led by the USAID/Health Communication for Life Project to inform the design of social accountability communication messages and interventions. The study also established baseline data on Malawians' knowledge, attitudes, and practices related to efficient use of government resources in the health sector.

Methods

This baseline, formative research study used a non-experimental, cross sectional survey design. Sampling for the mobile survey was conducted using the random digit dialing technique. Data were collected via mobile phone using interactive voice response technology. Our sample included 1,425 respondents, $67 \%$ of whom were male and $33 \%$ were female. Respondents were mostly 35 years old or younger, with more than half of female respondents reporting their age as 18-24 years.

Results

Our findings indicate that Malawians believe misuse of government resources is pervasive in Malawi. Seventy percent of men and nearly $60 \%$ of women reported having noticed, found, or seen drugs believed to be from a government health facility being sold elsewhere. Few respondents who had observed or experienced misuse of government health sector resources reported the incident. When asked the likelihood that they would report a request for a bribe, gift, or favor in exchange for health services in the future, $68 \%$ of respondents said they would report it.

Conclusions

Social and behavior change communication could serve a key role in motivating those who are aware of misuse of public sector health resources to report the issues they observe and providing them with the information needed to follow through. Further research is needed to understand the best approaches to mitigate underlying factors that drive misuse of resources and underreporting.
\end{abstract}

Key words: Government Resources; Health Sector; Accountability; Behavior Change; Corruption; Cross-Sectional Studies; Health Communication

\section{Introduction}

The negative effects of corruption and inefficient use or misuse of public resources on development are well documented. ${ }^{1-4}$ The Government of Malawi's (GoM) establishment of an Anti-Corruption Bureau in 1995 and the National Anti-Corruption Strategy in 2008 reflected the government's acknowledgement of the presence of corruption and its determination to address it. Unfortunately, the 2013 discovery of a massive plundering of government funds, locally referred to as Cashgate, called for renewed deliberation on the magnitude of corruption and how to effectively combat misuse of resources. Several studies have been conducted on public experiences with and perceptions of misuse of resources within public systems in Malawi. ${ }^{5}$ Although the studies' findings have been somewhat mixed, they have generally indicated that respondents perceived some small gains in reducing corruption over the last decade. ${ }^{6}$ Findings from the 2016 Afrobarometer/Transparency International survey, however, suggest a widespread public perception that the country is failing in its fight against corruption and that large proportions of Malawians reported being asked to pay bribes to access various public services. ${ }^{5}$ According to a 2016 Afrobarometer/Transparency International survey, half of all respondents believed that ordinary people can make no difference in the fight against corruption, and there was widespread fear that retaliation and other negative consequences may befall whistle-blowers. ${ }^{5}$

Research specifically on misuse of resources within the health sector in Malawi is sparse. A 2015 mixed-methods study conducted by the Malawi Health Sector Technical Assistance Project, the Ministry of Health, and the Options Consultancy identified various sources of inefficiencies within the health sector, as well as underlying factors that influence misuse of resources. ${ }^{8}$ With regard to mismanagement of essential drugs, the study found "leakage" was widespread, with health care workers taking drugs from health facility stocks without a prescription, effectively bypassing procedures for recording drug use and supplies that have been put into place to track stock and avoid leakage

While a variety of health system and governance reforms will be required to combat such misuse of government resources within the health sector, these changes can be 
facilitated by increasing public demand for accountability, improved reporting of suspected misuse of resources, and other client-driven changes.

\section{USAID/Health Communication for Life Project}

The USAID/Health Communication for Life (HC4L) Project in Malawi complements GoM anti-corruption efforts by promoting demand for efficient use of health sector resources as part of a social and behavioral change communication (SBCC) strategy. Under the GoM's National Health Communication Strategy (NHCS)-- Moyo ndi Mpamba: Usamalireni! (Life is Precious: Take Care of It!)_USAID/HC4L project is developing SBCC messages and interventions to be disseminated through mass media, community mobilization, and various other communication channels to promote social accountability for government resources in the health sector.

The cross-sectional knowledge, attitudes and practices (KAP) study reported here was led by USAID/HC4L project and was intended to inform both the design of the social accountability SBCC messages and interventions for USAID/HC4L project. The study also established baseline data on Malawians' knowledge, attitudes, and practices related to efficient use of government resources in the health sector. While the findings presented in this manuscript represent findings from the baseline study, evaluation of changes over the course of the five-year USAID/HC4L project will be assessed through an endline survey which will be implemented in late 2021. Specifically, the baseline study sought to:

Describe perceived misuse of government resources within the health system, according to Malawians

Describe Malawians' experiences with corruption within the health system

Describe Malawians' knowledge and use of reporting and accountability channels related to corruption

\section{Methods}

\section{Ethics Statement}

The KAP survey study was reviewed and approved by FHI 360's Protection of Human Subjects Committee and Malawi's National Committee on Research in the Social Sciences and Humanities. All participants were 18 years of age or older and informed consent was obtained from all respondents through a key press of 1 when asked if the respondent was willing to continue. No incentives or reimbursements were offered to participants.

\section{Study Design}

This baseline, formative research study used a cross sectional survey design. Sampling for the mobile survey was conducted using the random digit dialing (RDD) technique. $\mathrm{RDD}$ uses random number generators to produce potential Malawian phone numbers. Each subscriber identity module (SIM) card in Malawi had an equal chance of being selected into the sample. The calling number (also known as Caller ID or Sender ID) appeared as a local number from Malawi Airtel network or Telekom Networks Malawi, the two major mobile service providers in Malawi. Respondents did not incur airtime charges in completing the phone survey.

RDD and phone surveys are commonly used to generate a representative sample for population research in countries with high landline phone coverage because data collection is generally faster than household sampling and interviews and data may be less subject to interviewer effects than face-to-face interviews. ${ }^{9}$ RDD surveys on mobile phones may provide similar benefits to surveys conducted using landlines, especially in lower income countries like Malawi where mobile phones are more numerous than landline telephones. ${ }^{10-13}$

The sampling strategy was designed to allow assessment of changes in KAP related to use of government resources among Malawian adults ages 18-64 over the course of the project (i.e., baseline vs. endline). To detect a 10-point minimum difference (e.g., from $50 \%$ to $60 \%$ ) in the indicators of interest (e.g., exposure) with $90 \%$ power for a two-sided comparison (e.g., Year 1 to Year 5) with 5\% significance, a minimum of 519 completed surveys for each comparison group (i.e. male vs. female) at each data collection event (baseline vs. endline) was estimated.

\section{Measures and Data Collection}

The survey instruments were developed collaboratively with input from USAID/HC4L project technical staff, technical specialists from the U.S. Agency for International Development, and representatives from the Ministry of Health/Health Education Services (MOH-HES). The survey included the following measures:

Sociodemographic characteristics, including age range, region and district, relationship status, employment status and primary source of income, and education level

Individual perceptions and beliefs about the existence of corruption and misuse of resources in the health sector, their implications, and the most common forms of misuse

Individual experience and behavior related to health sector corruption, including:

noticing any drugs believed to be from a government health facility being sold in shops, markets, or private clinics, and what action was taken after seeing or noticing this;

how often a bribe was paid, a gift given, or a favor done for a health care worker at a public facility to get needed assistance if incidents were reported to a government official or someone in authority, authorities' actions against a health care worker involved in a reported bribery incident, and whether there was retaliation or negative consequences because of reporting the bribery incident.

Individual beliefs about barriers to reporting corruption and intentions/ willingness to report experiences of requests for bribes in the future

Data were collected via mobile phone using interactive voice response (IVR) technology. This technology uses pre-recorded audio files to communicate questions and the response choices to the respondent. IVR technology supports any combination of the 10 digits (0-9) as a response to a given question; all baseline survey questions were presented as a multiple-choice response format, with only one response choice allowed per question (i.e., no option for select all that apply). The questionnaires were administered in Chichewa (widely spoken in Malawi) and Chitumbuka (widely spoken in the northern region of the country). Survey respondents indicated their responses by pressing the corresponding digit on their phone's keypad. The digits were transmitted as key presses using a long-standing telecommunication signaling technology (DTMF, also known as touch tone) to the Viamo platform, which then recorded the question response 
associated with the digit pressed.

Each call began with an initial multiple-choice question asking the respondent to choose the language in which to complete the survey, followed by a question to obtain informed consent (as indicated by pressing " 1 " to start). All respondents ages 18-64 years were eligible for participation. All questions and responses were presented in the same order for all respondents; the survey included a maximum of 30 questions and variations in the number of questions answered per respondent were due to survey skip patterns.

\section{Data Analysis}

Response, cooperation, and refusal rates were calculated using the Outcome Calculator of the American Association for Public Opinion Research (AAPOR) ${ }^{15}$. Summary statistics were generated using STATA 13 for Windows ${ }^{16}$. Descriptive analyses were performed, and percentages were computed for responses across survey items. Analyses were stratified by gender. All results are presented as unweighted.

\section{Results}

\section{Characteristics of Study Respondents}

Sampling, recruitment, and data collection were completed concurrently over an eight-day period in July 2017. The survey had a total dialed sample of 928,271, of which a large proportion were non-working numbers-which is common in RDD survey research using mobile phones. ${ }^{14}$ There was also a relatively large proportion of calls that were "picked up" where it was impossible to determine eligibility as the first question on language selection was not completed; this could be due to hang ups by potential respondents, network errors, non-working numbers, or other technology problems. Our estimated response rate was about $6 \%$, the cooperation rate was $19 \%$, the refusal rate was $21 \%$, and the contact rate was $32 \%$. Our final sample included 1,425 respondents, $67 \%$ of whom were male and $33 \%$ of whom were female (Table 1). Respondents were primarily 35 years of age or younger, with more than half of female respondents reporting their age as 18-24 years. Overall, just over half of survey respondents were from the Central Region, while more than one-third were from the Southern Region. Regarding educational attainment, just over half of respondents had completed junior secondary or higher education, with the remainder split between those with no education and those who reported completing primary school only. Both male and female respondents most commonly reported having a full-time job outside the home or working as a day laborer for wages, followed by working on their own property or farm. More than $10 \%$ of women reported staying home as a homemaker. When asked about their primary source of income, men and women most commonly named farming, followed by trade, "other," and education. Health was the least common source of income.

\section{Perceptions and Beliefs Related to Misuse of Resources}

When participants were asked if they felt corruption was a problem in Malawi, an overwhelming $94 \%$ of respondents reported corruption is a major problem. Those who responded affirmatively were asked whether they believed there to be corruption in the health sector, to which $64 \%$ of women and $71 \%$ of men responded positively (Table 2 ).

When given three options as to their perception of the most serious problems caused by corruption in the health
Table 1. Characteristics of study respondents

\begin{tabular}{|c|c|c|c|c|c|c|}
\hline & \multicolumn{2}{|c|}{ Female } & \multicolumn{2}{|c|}{ Male } & \multicolumn{2}{|c|}{ Total } \\
\hline & $n=467$ & $\%$ & $n=958$ & $\%$ & $\mathrm{~N}=1,425$ & $\%$ \\
\hline \multicolumn{7}{|l|}{ Age } \\
\hline $18-24$ & 263 & $56 \%$ & 431 & $45 \%$ & 694 & $49 \%$ \\
\hline $25-35$ & 145 & $31 \%$ & 329 & $34 \%$ & 474 & $33 \%$ \\
\hline $36-49$ & 50 & $11 \%$ & 149 & $16 \%$ & 199 & $14 \%$ \\
\hline 50 or older & 9 & $2 \%$ & 49 & $5 \%$ & 58 & $4 \%$ \\
\hline \multicolumn{7}{|l|}{ Region } \\
\hline Central & 207 & $44 \%$ & 513 & $54 \%$ & 720 & $51 \%$ \\
\hline Northern & 85 & $18 \%$ & 142 & $15 \%$ & 227 & $16 \%$ \\
\hline Southern & 175 & $38 \%$ & 303 & $32 \%$ & 478 & $34 \%$ \\
\hline \multicolumn{7}{|l|}{$\begin{array}{l}\text { Highest education } \\
\text { completed }\end{array}$} \\
\hline No education & 85 & $18 \%$ & 208 & $22 \%$ & 293 & $21 \%$ \\
\hline Primary & 91 & $19 \%$ & 211 & $22 \%$ & 302 & $21 \%$ \\
\hline Junior secondary & 79 & $17 \%$ & 138 & $14 \%$ & 217 & $15 \%$ \\
\hline $\begin{array}{l}\text { Senior } \\
\text { secondary }\end{array}$ & 108 & $23 \%$ & 210 & $22 \%$ & 318 & $23 \%$ \\
\hline $\begin{array}{l}\text { Vocational or } \\
\text { technical }\end{array}$ & 45 & $10 \%$ & 95 & $10 \%$ & 140 & $10 \%$ \\
\hline Tertiary or higher & 59 & $12 \%$ & 96 & $10 \%$ & 77 & $10 \%$ \\
\hline \multicolumn{7}{|l|}{ Marital status } \\
\hline Single & 203 & $44 \%$ & 296 & $31 \%$ & 499 & $35 \%$ \\
\hline $\begin{array}{l}\text { Married or living } \\
\text { with a partner }\end{array}$ & 213 & $46 \%$ & 623 & $65 \%$ & 836 & $59 \%$ \\
\hline $\begin{array}{l}\text { Separated or } \\
\text { divorced }\end{array}$ & 49 & $11 \%$ & 29 & $3 \%$ & 78 & $5 \%$ \\
\hline Widowed & 2 & $0 \%$ & 10 & $1 \%$ & 12 & $1 \%$ \\
\hline \multicolumn{7}{|l|}{ Employment status } \\
\hline $\begin{array}{l}\text { Full-time job } \\
\text { outside the home }\end{array}$ & 111 & $24 \%$ & 296 & $31 \%$ & 407 & $29 \%$ \\
\hline $\begin{array}{l}\text { Day laborer for } \\
\text { wages }\end{array}$ & 111 & $24 \%$ & 279 & $29 \%$ & 390 & $27 \%$ \\
\hline $\begin{array}{l}\text { Day laborer for } \\
\text { food or lodging }\end{array}$ & 24 & $5 \%$ & 36 & $4 \%$ & 60 & $4 \%$ \\
\hline $\begin{array}{l}\text { Work on own } \\
\text { property or farm }\end{array}$ & 71 & $15 \%$ & 136 & $14 \%$ & 207 & $15 \%$ \\
\hline $\begin{array}{l}\text { Stay home as } \\
\text { homemaker }\end{array}$ & 64 & $14 \%$ & 51 & $5 \%$ & 115 & $8 \%$ \\
\hline Unemployed & 37 & $8 \%$ & 53 & $6 \%$ & 90 & $6 \%$ \\
\hline Other & 49 & $11 \%$ & 107 & $11 \%$ & 156 & $11 \%$ \\
\hline \multicolumn{7}{|l|}{$\begin{array}{l}\text { Primary source of } \\
\text { income }\end{array}$} \\
\hline Farming & 159 & $34 \%$ & 432 & $45 \%$ & 591 & $41 \%$ \\
\hline Education & 67 & $14 \%$ & 128 & $13 \%$ & 195 & $14 \%$ \\
\hline Health & 21 & $5 \%$ & 28 & $3 \%$ & 49 & $3 \%$ \\
\hline Trade & 119 & $25 \%$ & 165 & $17 \%$ & 284 & $20 \%$ \\
\hline Other & 101 & $22 \%$ & 205 & $21 \%$ & 306 & $21 \%$ \\
\hline
\end{tabular}

sector, more than $60 \%$ of respondents indicated "shortage or unavailability of medicines" as the most serious problem, while more than one-quarter indicated "longer wait times or unequal access to services" (Table 2). When given five options as to the most common corrupt practices in the 
Table 2. Participant's beliefs about corruption in Malawi health sector

\begin{tabular}{|c|c|c|c|c|c|c|}
\hline & \multicolumn{2}{|c|}{ Female } & \multicolumn{2}{|c|}{ Male } & \multicolumn{2}{|c|}{ Total } \\
\hline & $\bar{n}$ & $\%$ & $\mathrm{n}$ & $\%$ & $\mathrm{~N}$ & $\%$ \\
\hline $\begin{array}{l}\text { Perception that corruption exists in the health sector } \\
\text { (among those who believe corruption is a problem in Malawi) }\end{array}$ & 455 & & 937 & & 1,392 & \\
\hline Yes & 293 & $64 \%$ & 666 & $71 \%$ & 959 & $69 \%$ \\
\hline No & 69 & $16 \%$ & 126 & $13 \%$ & 195 & $14 \%$ \\
\hline Not sure & 93 & $20 \%$ & 145 & $15 \%$ & 238 & $17 \%$ \\
\hline $\begin{array}{l}\text { Perception of the most serious problem caused by corruption in the health sector (among those who believe corruption exists } \\
\text { in the health sector) }\end{array}$ & 293 & & 666 & & 959 & \\
\hline Shortage or unavailability of medicines & 178 & $61 \%$ & 437 & $66 \%$ & 615 & $64 \%$ \\
\hline Longer wait times or unequal access to services & 88 & $30 \%$ & 167 & $25 \%$ & 255 & $27 \%$ \\
\hline Distrust in health service providers & 27 & $9 \%$ & 62 & $9 \%$ & 89 & $9 \%$ \\
\hline $\begin{array}{l}\text { Perception of the most common corrupt practice in the health sector } \\
\text { (Among those who believe corruption exists in the health sector) }\end{array}$ & 293 & & 666 & & 959 & \\
\hline Bribes & 61 & $21 \%$ & 142 & $21 \%$ & 203 & $21 \%$ \\
\hline Fraud & 30 & $10 \%$ & 83 & $12 \%$ & 113 & $12 \%$ \\
\hline Informal payments for free services & 110 & $38 \%$ & 169 & $25 \%$ & 279 & $29 \%$ \\
\hline Theft or misuse of property & 76 & $26 \%$ & 255 & $38 \%$ & 331 & $35 \%$ \\
\hline Absenteeism & 16 & $5 \%$ & 17 & $3 \%$ & 33 & $3 \%$ \\
\hline
\end{tabular}

Table 3. Participant's exposure to and practices around corruption in Malawi health sector

\begin{tabular}{|c|c|c|c|c|c|c|}
\hline & \multicolumn{2}{|c|}{ Female } & \multicolumn{2}{|c|}{ Male } & \multicolumn{2}{|c|}{ Total } \\
\hline & $\mathbf{n}$ & $\%$ & $\mathrm{n}$ & $\%$ & $\mathbf{N}$ & $\%$ \\
\hline $\begin{array}{l}\text { Noticed, found, or seen any drugs believed to be from a government health facility being sold } \\
\text { anywhere, including shops, market, and private clinics }\end{array}$ & 467 & & 958 & & 1,425 & \\
\hline Yes & 277 & $59 \%$ & 671 & $70 \%$ & 948 & $67 \%$ \\
\hline No & 190 & $41 \%$ & 287 & $30 \%$ & 477 & $33 \%$ \\
\hline Action taken after seeing or noticing this: & 277 & & 671 & & 948 & \\
\hline Reported to police & 26 & $9 \%$ & 77 & $11 \%$ & 103 & $11 \%$ \\
\hline Reported to local chief & 20 & $7 \%$ & 62 & $9 \%$ & 82 & $9 \%$ \\
\hline Reported to Anti-Corruption Bureau & 5 & $2 \%$ & 21 & $3 \%$ & 26 & $3 \%$ \\
\hline Never took any action & 226 & $82 \%$ & 511 & $76 \%$ & 737 & $78 \%$ \\
\hline $\begin{array}{l}\text { In the last } 12 \text { months, how often a bribe was paid, gift given, or favor done for a health care } \\
\text { worker at a public facility by a respondent to get the needed assistance }\end{array}$ & 467 & & 958 & & 1,425 & \\
\hline Never & 364 & $78 \%$ & 720 & $75 \%$ & 1,084 & $76 \%$ \\
\hline Once or twice & 34 & $7 \%$ & 96 & $10 \%$ & 130 & $9 \%$ \\
\hline A few times & 13 & $3 \%$ & 19 & $2 \%$ & 32 & $2 \%$ \\
\hline Often & 48 & $10 \%$ & 108 & $11 \%$ & 156 & $11 \%$ \\
\hline Cannot recall & 8 & $2 \%$ & 15 & $2 \%$ & 23 & $2 \%$ \\
\hline $\begin{array}{l}\text { Reported incidents to a government official or someone in authority } \\
\text { (among those experiencing corruption in last } 12 \text { months) }\end{array}$ & 95 & & 223 & & 318 & \\
\hline Yes & 13 & $14 \%$ & 40 & $18 \%$ & 53 & $17 \%$ \\
\hline No & 82 & $86 \%$ & 183 & $82 \%$ & 265 & $83 \%$ \\
\hline $\begin{array}{l}\text { Authorities acted against the health care worker involved in reported bribery incident (among } \\
\text { those who reported it) }\end{array}$ & 13 & & 40 & & 53 & \\
\hline No, didn't happen & 7 & $54 \%$ & 28 & $70 \%$ & 35 & $66 \%$ \\
\hline Yes, happened & 4 & $31 \%$ & 5 & $13 \%$ & 9 & $17 \%$ \\
\hline Don't know & 2 & $15 \%$ & 7 & $18 \%$ & 9 & $17 \%$ \\
\hline $\begin{array}{l}\text { Suffered retaliation or negative consequences because of reporting bribery incident (among } \\
\text { those who reported it) }\end{array}$ & 13 & & 40 & & 53 & \\
\hline No, didn't happen & 7 & $54 \%$ & 26 & $65 \%$ & 33 & $62 \%$ \\
\hline Yes, happened & 6 & $46 \%$ & 14 & $35 \%$ & 20 & $38 \%$ \\
\hline Don't know & 0 & $0 \%$ & 0 & $0 \%$ & 0 & $0 \%$ \\
\hline
\end{tabular}


Table 4. Participant's perceptions and intentions of reporting misuse of health sector resources

\begin{tabular}{|c|c|c|c|c|c|c|}
\hline & \multicolumn{2}{|c|}{ Female } & \multicolumn{2}{|c|}{ Male } & \multicolumn{2}{|c|}{ Total } \\
\hline & $\mathrm{n}$ & $\%$ & $\mathrm{n}$ & $\%$ & $\mathrm{~N}$ & $\%$ \\
\hline Main reason people do not report corruption & 467 & & 958 & & 1425 & \\
\hline Most people DO report incidents of corruption & 59 & $13 \%$ & 94 & $10 \%$ & 153 & $11 \%$ \\
\hline Corruption is too difficult to report & 134 & $29 \%$ & 281 & $29 \%$ & 415 & $29 \%$ \\
\hline People don't know how to report corruption & 150 & $32 \%$ & 313 & $33 \%$ & 463 & $32 \%$ \\
\hline People don't believe reporting corruption would make a difference & 39 & $8 \%$ & 67 & $7 \%$ & 106 & $7 \%$ \\
\hline People are afraid of the consequences of reporting corruption & 55 & $12 \%$ & 120 & $13 \%$ & 175 & $12 \%$ \\
\hline Other & 30 & $6 \%$ & 83 & $9 \%$ & 113 & $8 \%$ \\
\hline $\begin{array}{l}\text { The most important way ordinary people can make a difference in the fight against corruption like } \\
\text { drug theft, bribery, and theft of other items from health facilities }\end{array}$ & 467 & & 958 & & 1425 & \\
\hline Reporting incidents to local authorities & 152 & $33 \%$ & 322 & $34 \%$ & 474 & $33 \%$ \\
\hline Refusing to give or take bribes & 201 & $43 \%$ & 410 & $43 \%$ & 611 & $43 \%$ \\
\hline Talking to others about fighting corruption & 114 & $24 \%$ & 226 & $24 \%$ & 340 & $24 \%$ \\
\hline Where or to whom would you report an incident of bribery? & 467 & & 958 & & 1425 & \\
\hline Police & 113 & $24 \%$ & 246 & $26 \%$ & 359 & $25 \%$ \\
\hline Local chief & 95 & $20 \%$ & 235 & $25 \%$ & 330 & $23 \%$ \\
\hline Anti-Corruption Bureau & 125 & $27 \%$ & 247 & $26 \%$ & 372 & $26 \%$ \\
\hline Someone else & 26 & $6 \%$ & 43 & $4 \%$ & 69 & $5 \%$ \\
\hline Don't know & 108 & $23 \%$ & 187 & $20 \%$ & 295 & $21 \%$ \\
\hline Likelihood of reporting request of bribe, gift, or favor to receive services in the future & 467 & & 958 & & 1425 & \\
\hline I would report it & 294 & $63 \%$ & 671 & $70 \%$ & 965 & $68 \%$ \\
\hline I might report it & 112 & $24 \%$ & 210 & $22 \%$ & 322 & $23 \%$ \\
\hline I would not report it & 61 & $13 \%$ & 77 & $8 \%$ & 138 & $10 \%$ \\
\hline
\end{tabular}

health sector, most respondents reported "theft or misuse of property" and "informal payments for free services" (Table 3). An estimated $79 \%$ of respondents believed it was wrong for a health worker to take malarial drugs from a public clinic to sell them for a profit.

\section{Experience, Behaviors, and Intentions Related to Misuse of Resources}

Study participants were asked about their personal exposure to and experience with two types of misuse of government resources in the health sector: selling government facility drugs for profit and payment of bribes. Seventy percent of men and nearly $60 \%$ of women reported having noticed, found, or seen drugs believed to be from a government health facility being sold elsewhere (including shops, markets, and private health facilities) (Table 3). Nearly onequarter of respondents reported they had paid a bribe or given a gift to a health care worker at a public facility in the last 12 months in order to receive services, and of these, more than $11 \%$ reported that they had paid bribes often. In both circumstances, few respondents who had observed or experienced misuse of government health sector resources reported the incident.

When respondents were asked about their perception of the primary reason people in Malawi do not report corruption, lack of knowledge on how to report corruption and the perception that corruption is too difficult to report were the most common responses; only a small proportion reported that most people do report incidents (Table 4). Perhaps reflecting this knowledge gap, respondents were largely split across four response options as to whom they would report an incident of bribery: the anti-corruption Bureau, the police, the local chief, or they said they did not know. Despite this gap, when asked the likelihood that they would report a request for a bribe, gift, or favor in exchange for health services in the future, a strong majority of respondents $(68 \%)$ said they would definitely report it and $23 \%$ said they might report it.

\section{Discussion}

Our KAP survey findings provide a descriptive basis to inform SBCC programming, including areas where current knowledge gaps exist, and quick gains may be possible. Our findings indicate that Malawians believe misuse of government resources is pervasive in Malawi and that many have personally observed or experienced corruption within the last year, although reporting incidents was low. Our findings are an important triangulation to Carlson et al.'s findings that providers themselves report widespread "leakage" of medications and the 2016 Afrobarometer \& Transparency International survey findings that large proportions of Malawians reported being asked to pay bribes to access various public services. ${ }^{5}$ Likewise, we found some evidence that Malawian's lack trust in reporting mechanisms, including a belief that reporting corruption will not make a difference and that reporting corruption could result in retaliation. This pattern reflects previous scholarship in Malawi that indicates an overall lack of trust in public institutions, reinforcing reliance on personal networks. ${ }^{17-19}$ Despite finding that few have reported incidents of corruption, in our study many reported a willingness to report an incident in the future. Capitalizing on this motivation will require overcoming barriers to reporting that were highlighted in our findings. 


\section{Limitations}

While our results are descriptive, further analysis of the data, beyond descriptive analyses, should take population-based weighting into account to correct for sampling bias. Mobile phone surveys underrepresent population groups with less access to mobile phones, including rural residents and women. Our low response rates also indicate the possibility of nonresponse bias, although response rates are typically lower for mobile phone surveys compared to face to face research or research using established landline sampling frames. ${ }^{15}$ Social desirability bias, common to formative studies, may have influenced our findings due to respondents' hope that providing positive feedback on questions will cause them to be rewarded or viewed as socially acceptable, although the anonymous nature of mobile surveying may have facilitated more objective responses? ${ }^{9}$. Further research using complementary study designs would aid in triangulating our results, including population-based household survey, structured observations, and qualitative data collection.

\section{Recommendations}

SBCC programming could serve a key role in motivating and enabling individual citizens who are aware of potentially corrupt practices to report the issues. Increased knowledge of different forms of misuse of government resources such as fraud and absenteeism, as well as ways to report experiences or observations of corruption, could be achieved through amplifying awareness of social accountability interventions through mass and social media. The agencies handling corruption or misuse cases should build partnerships with media houses to publish or broadcast the number of corruption cases prosecuted to instill confidence that reporting yields results. These efforts may serve a dual purpose of increasing awareness of how to report and building public trust and confidence that reports are confidential and will be acted on. In addition, the effectiveness of concerted SBCC programming to promote positive norms around protecting public resources for everyone's benefit could be explored. Results of such strategies should be closely monitored, as further evidence on effective SBCC strategies to counter lack of trust amid ongoing and large-scale political scandals is needed.

A coordinated social accountability communication and advocacy plan that works in partnership with civil society accountability partners at the national and district levels would aid these efforts. Local platforms such as the volunteer Health Centre Advisory Committees (HCAC) outlined in the GoM's Health Sector Strategic Plan II (2017-2022) and the Malawi National Community Health Strategy (2017-2022) presents an opportunity to strengthen community ability to demand adequate, high quality services. HCAC's have a mandate to monitor the use of health facility resources, such as drugs, and constraints preventing service delivery, including absenteeism, corruption, and misuse of government resources. However, it is unclear the extent to which this platform is operational across the country. SBCC programming designed to target public servants and providers may also be useful to promote norms around honoring formal bureaucratic norms and rules, such as anti-corruption laws and statutes, while mitigating concerns about implications for kinship networks, status, and social capital that may be perceived to be undermined by working through newer or untried mechanisms.
However, SBCC messaging can only go so far to ensure the protections that should be in place for those who choose to report fraudulent or corrupt behaviors. Government agencies, police, and other involved organizations must ensure the safety and anonymity of people who report incidents. Government should strengthen structures to improve the response to reports of abuse of resources to prevent people from becoming demoralized if no action is taken.

\section{Conclusion}

Malawi's improvements in most health indicators over the past two decades were achieved by focusing on the improved delivery of essential health services, including reducing maternal mortality and increasing child survival, improving contraception prevalence, and reducing HIV prevalence. For these advances to continue, however, the country must overcome challenges posed by high unmet need for FP services, HIV incidence, diarrhea, malnutrition and stunting, high burden of malaria, and poor access to improved sanitation facilities. Such tremendous health challenges place an onerous burden on the health system, which is exacerbated by a lack of accountability for the resources the health sector does have, an issue that is at the forefront due to recent reports that underscore longstanding issues of drug pilferage and misuse of government funds. While not explored in our study, perceptions of corruption within public health facilities may also contribute to delayed care seeking or seeking care from unqualified sources. SBCC efforts and partnerships with civil society actors can play an important role in building public awareness of reporting mechanisms, trust in public institutions, and demand for accountability.

\section{Acknowledgements}

Author Contributions: AM, GT, RL, CG, HF, and BN made substantial contributions to the conception and design of the study; All authors made substantial contributions to analysis or interpretation of data and drafting or revising the article. All authors have approved the final version of the manuscript.

\section{Statement on Conflict of Interest Funder Acknowledgement}

OtherSubstantial Contributors: Tom Mortimore and Prashant Singh of Viamo contributed significantly to programming and executing RDD and IVR survey, data cleaning and reporting; Natalie Eley, MPH, and Thaddeus Pennas, both from FHI 360's GHPN Department contributed to protocol and questionnaire development; Robert Chizimba, Amos Zikusooka, and other technical advisors from the USAID/ HC4L project; Tobias Kunkumbira and Hector Kamkwamba of $\mathrm{MOH} / \mathrm{HES}$ supported questionnaire development.

\section{References}

1.Lambsdorff JG. How corruption affects economic development. Transparency International Global Corruption Report 2004. London: Pluto Press; 2004. p. 310-312.

2. Akçay S. Corruption and human development. Cato Journal. 2006;26(1):29-46.

3. Runde DF, Hameed S, Magpile J. The cost of corruption: strategies for ending a tax on private-sector-led growth. New York: Rowman and Littlefield; 2014. 
4. Banerjee R. Corruption, norm violation and decay in social capital. Journal of Public Economics. 2016; 137:14-27.

5. Chunga JJ, Mazalale J. Is Malawi losing the battle against 'Cashgate'? Afrobarometer Dispatch No. 149. Afrobarometer and University of Malawi; 2017. Available from: http://afrobarometer.org/sites/default/ files/publications/Briefing\%20papers/ab dispatchno149 corruption in_malawi_1.pdf.

6. Nawaz F. Overview of corruption and anti-corruption in Malawi. Transparency International, Chr. Michelsen Institute; 2012. Available from: https://www.u4.no/publications/overview-of-corruption-andanti-corruption-in-malawi.pdf.

7. International Foundation for Electoral Systems (IFES), Millennium Consulting Group Ltd. Malawi governance and corruption baseline survey. Lilongwe; 2006. Available from: http://siteresources.worldbank. org/INTWBIGOVANTCOR/Resources/1740479-1143042582963/ malawi_final_survey.pdf.

8. Carlson C, Chirwa W, Hall N. Study of health sector efficiency in Malawi. Lilongwe: Ministry of Health and Options Consultancy Ltd.; 2015. Available from: https://www.academia.edu/23732303/Study_of_ Health_Sector_Efficiency_in_Malawi.

9. Kempf AM, Remington PL. New challenges for telephone survey research in the twenty-first century. Annu Rev Public Health 2007;28:113-26. DOI: 10.1146/annurev.publhealth.28.021406.144059.

10. World Bank. World development report 2016: digital dividends. Washington, DC: World Bank; 2016. Available from: http://www. worldbank.org/en/publication/wdr2016.

11. Gallup. Disparities in cell phone ownership pose problems in Africa. Washington, DC: Gallup; 2016. Available from : http://www.gallup. com/poll/189269/disparities-cellphone-ownership-posechallenges- africa.aspx.

12. Hu SS, Balluz L, Battaglia MP, Frankel MR. The impact of cell phones on public health surveillance. Bull World Health Organ. 2010;88:799. DOI: 10.2471/BLT.10.082669.

13. Mahfoud Z, Ghandour L, Ghandour B, Mokdad A, Sabai A. A comparison of cell phone and face to face interviews in populationbased surveys. Field Methods. 2015;27:39-54.

14. L'Engle K, Sefa E, Akolgo Adimazoya E, Yartey E, Lenzi R, Tarpo C, Heward-Mills NL, Lew K, Ampeh Y. Survey research with a random digit dial national mobile phone sample in Ghana: methods and sample quality. PLOS ONE. 2018;13(1): e0190902. https://doi.org/10.1371/ journal.pone.0190902

15. American Association for Public Opinion Research (AAPOR) [Internet]. Response rates calculations; [cited 2019 June 17]. Available from: http://www.aapor.org/Education-Resources/For-Researchers/ Poll-Survey-FAQ/Response-Rates-An-Overview.aspx.

16. StataCorp. Stata statistical software: release 13. College Station, TX: StataCorp LP; 2013.

17. Anders G. Like chameleons. Civil servants and corruption in Malawi. Bulletin de l'APAD. 2002;23-24.

18. Goldberg A, Ilana RL. Understanding the intrinsic motivation of health workers in Malawi. Abt Associates; 2013.

19. Hussein M. Combating corruption in Malawi. An assessment of the enforcing mechanisms. African Security Review. 2004;14(4): 91-101. 